\title{
HORTICULTURE OF NUTMEG: GERMINATION, PROPAGATION AND CULTIVATION
}

\author{
Bob (W.N.J.) Ursem ${ }^{1}$, Winarko Boesrie ${ }^{2} \&$ Erwin Kluver $^{3}$
}

\begin{abstract}
The living collection of plants in the nutmeg family, Myristicaceae, has been increasing at the Botanic Garden of Delft University of Technology (Delft BG) since 2001. Horticultural and research staff there have been exploring the horticultural requirements, molecular structure and chemical composition of these plants since then. This paper comments on the historical importance of this family and the processes required to acquire live plant material.

In recent years the significance of the mycorrhizal associations formed by the family and the consequences for their cultivation have been identified and these are described here along with the most effective methods of propagation as identified by staff at Delft BG.
\end{abstract}

\section{INTRODUCTION}

The Botanic Garden of Delft University of Technology (Delft BG) was founded in 1917 and was the very first garden in the world which focused on economically valuable plants, providing trees for wood, fibres, dyes, resins, gums, latex and other secondary metabolites and herbs for fibres, dyes and oil for industry. The early 1900s were a time of rapid change and industrial development (Van Mourik \& Van der Veen, 2008) and many plants and their potential for human use were unknown. As a consequence of its economic focus, the Garden has strong historic links to Indonesia and its adjacent areas as this is where many of the plants that became economically important either originated or were farmed. Among the collections of useful plants which Delft BG now cultivates, there are several genera in the nutmeg family, Myristicaceae. These are Myristica, Knema, Horsfieldia, Brochoneura and Gymnacranthera. The five genera grown at Delft BG are only a small representation of this family as there are 16 other genera which occur in tropical Asia and the Pacific basin. Staff at Delft BG believe that due to the chemicals and compounds present in these plants, their potential value to science is not fully known, and it is for this reason that new horticultural research is being undertaken. Furthermore, molecular information for the family is not well known either. The genera listed above are known to be difficult plants to grow and are therefore rarely seen in botanic gardens. Staff at Delft BG identified opportunities to explore the cultivation of these genera in order to contribute knowledge to the horticulture, molecular structure

1. Bob Ursem is Director of Science at the Botanic Garden of Delft University of Technology and corresponding author for this article.

Address: Department of Biotechnology, Faculty of Applied Sciences, Julianalaan 67, NL-2628 BC Delft, The Netherlands. Email: W.N.J.Ursem@TUDelft.nl

2. Winarko Boesrie is Glasshouse Horticulturist at the Botanic Garden of Delft University of Technology.

3. Erwin Kluver is Head Gardener at the Botanic Garden of Delft University of Technology. 
and chemical composition of the family. The nutmeg plants are still very young, and very few plants have flowered so far. Meanwhile, however, staff have gained a lot of experience in their germination, propagation and growing requirements, which is worth sharing here.

\section{ACQUIRING THE COLLECTIONS}

Delft BG has been sourcing wild collected and pre-germinated seeds from Indonesian and Indian regions since 2001. Some have come from wild populations and others from forestry plantations and botanic gardens. The seeds and plants have been collected by a number of local plant collectors, forestry staff and botanically trained volunteers. Species have been collected from the Indonesian islands (mainly Tidore), Papua New Guinea, the Fiji islands, the Philippines and Malaysia. Seeds and pre-germinated wildcollected seeds have been supplied by the Forestry Departments of India, mainly from the following districts: Tamil Nadu, Kerala, Andhra Pradesh, Orissa and Kamantaka. Some seeds have been obtained and sent by botanic gardens, including Bogor Botanic Gardens in Indonesia, the National Botanic Gardens of Papua New Guinea and Port Moresby Nature Park/National Capital Botanic Gardens in Papua New Guinea, and Suva Botanical Gardens in Fiji. Delft BG has provided the funds for the field trips and the cost of transporting the seeds to Delft. Both the Forestry Departments and the botanic gardens that have provided these seeds maintain duplicate collections in seed beds and grow these plants in their gardens.

The Dutch were the very first traders of nutmegs in the world - and the Botanic Garden of Delft University had a historical relationship with Indonesia through the use of the plants in trade and industry. In addition, because most members of the Myristicaceae originate from the Indonesian islands and there was already some knowledge of interest to science (such as the chemical components, genetics and some of the cultivation requirements), it occurred to staff at Delft BG that Myristicaceae would be a good choice for a new research focus for the Garden. In the early years of the project it was difficult to obtain good quality material and staff had to invest in a practical and effective system of quick transportation of seeds which was compliant with regulations. The outcome needed to be of value to both Delft BG and the organisations sending the material, at a low cost and with locally available packing materials. A system was established whereby seeds were harvested and then pre-treated in the 'nutmeg' soil at the local Forestry Station, from locations near or under an old nutmeg tree. Many collectors, including plant collectors, forestry staff and amateur and professional field botanists, use the same technique. After up to a week at the Forestry Station or in the collector's back garden, seeds start to swell or produce a small first root-tip. The seeds with a distinct swollen radicle or with a primary root are then surrounded by wet woodchips in sealed styrofoam boxes and sent by air to Delft under controlled temperature conditions as special cargo. 


\section{SEED TREATMENT IN DELFT}

Nutmegs are known to be difficult to germinate and cultivate. The seeds are large but have extremely limited dormancy and fertility after the seed has matured, meaning that the optimum time for germination will only last for a maximum of a few weeks.

When the boxes are opened in Delft the seeds are carefully removed and potted in a mixture of one-third lava grains and two-thirds basic mixture of 30 per cent sand and 70 per cent peat. A small sample of old ectomycorrhiza-rich soil is placed near the seed-germination point. This has been taken from mature plants in the forestry-grown collection. This soil sample was very difficult to obtain due to phytosanitary regulations and restrictions; however importation was finally approved in 2001.

The seeds are positioned sideways in pots to develop, with the germination tip just under the soil surface, and are kept in a seed germination incubator with bottom heat. Germination normally takes one week, but may take up to a maximum of three weeks. Seeds that arrive with a primary root already developed need approximately one week to adapt to the greenhouse conditions at Delft BG. The germinated seed needs to connect to the ectomycorrhiza as soon as possible for the plant to grow well.

\section{ECTOMYCORRHIZAL ASSOCIATIONS}

Mycorrhiza are fungi which form an association with plant roots to the mutual benefit of both fungus and plant (Smith \& Read, 2008). Ectomycorrhiza are a type of mycorrhiza that most commonly form associations with a range of woody species (Walker, 2013) and are known to be important for optimal plant growth (Baar \& Ozinga, 2007). The presence of ectomycorrhiza in soil samples can be easily recognised on roots by the presence of a structure known as the 'Hartig net' (Baar \& Ozinga, 2007) (Fig. 1). Whilst a lot of research has been conducted on the value of mycorrhiza for plant growth there has been little research on mycorrhizal associations in pot-grown plants, particularly on tropical species. Without the presence of ectomycorrhiza there is no uptake of nutrients in exchange for carbohydrates (Baar \& Ozinga, 2007).

Ectomycorrhiza fungi develop into a net share of abundant growth consisting of very slender hyphae with a diameter of $0.0003 \mathrm{~mm}$. The ectomycorrhiza covers the rhizodermis and exodermis of the roots like a cloak and its hyphae penetrate into the parenchyma and further (endodermis, phloem and xylem) to envelop the plant cells (Fig. 2). All other mycorrhizal fungi, known as arbuscular mycorrhiza, ericoide mycorrhiza and ectendomycorrhiza, penetrate the host's cells and are not visible from the outside.

As soon as the primary root grows out of the seed, it needs to connect to the ectomycorrhiza to take up nitrogen as well as inorganic nutrients (Figs 3 and 4). At Delft BG fertiliser containing phosphorus is not used because it has been observed that nutmegs do not respond well to additional phosphorus in the soil. The investigation into the reason for this will be part of a future research project. The exchange of nutrients, sugar and water takes place in the Hartig net or between the hyphae of the ectomycorrhiza and 

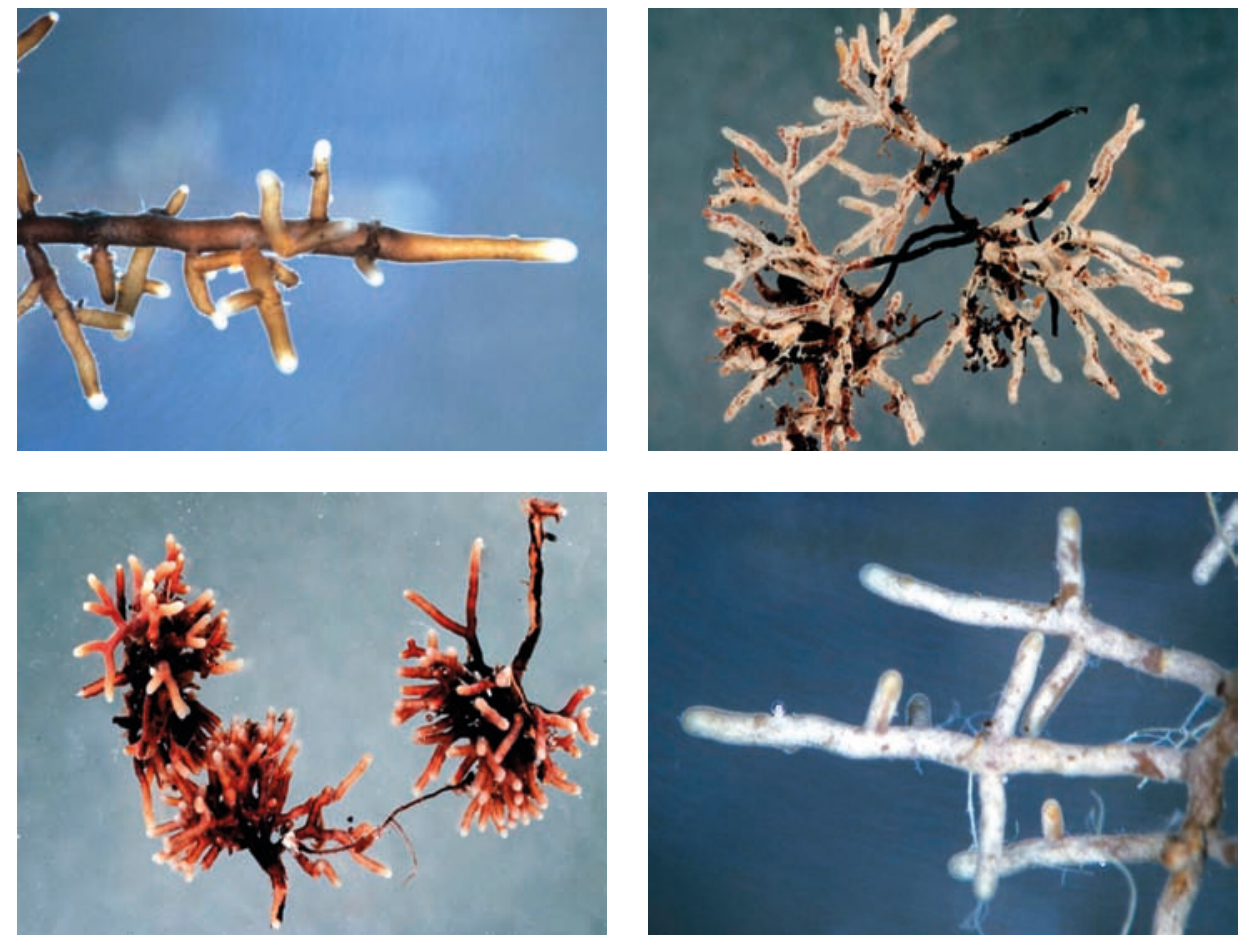

Fig. 1 Above left: plant root tips with mycorrhiza. Above right: total coverage of plant roots by a 'Hartig net' of mycorrhiza. Bottom left: a series of root tip growths with mycorrhiza beginning to cover them. Bottom right: Hartig net encircling the root tips and beginning to penetrate the central root system. Permission to reproduce these images was kindly given by Peterson et al. (2006).

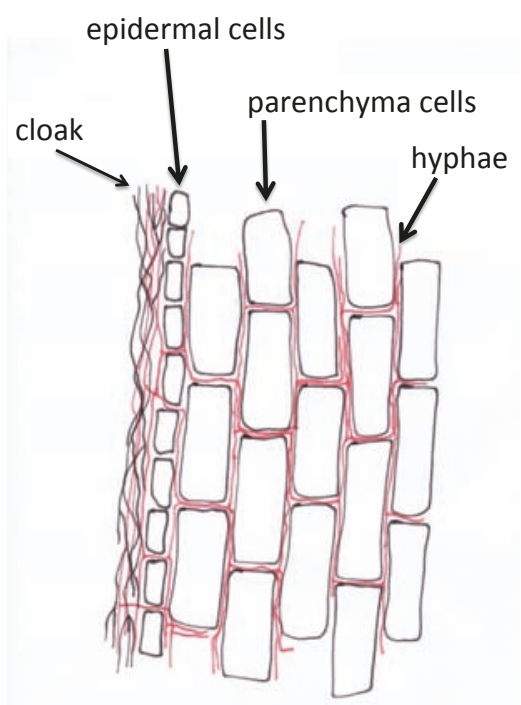

Fig. 2 Ectomycorrhiza penetration in root systems. Drawing: Bob Ursem. 

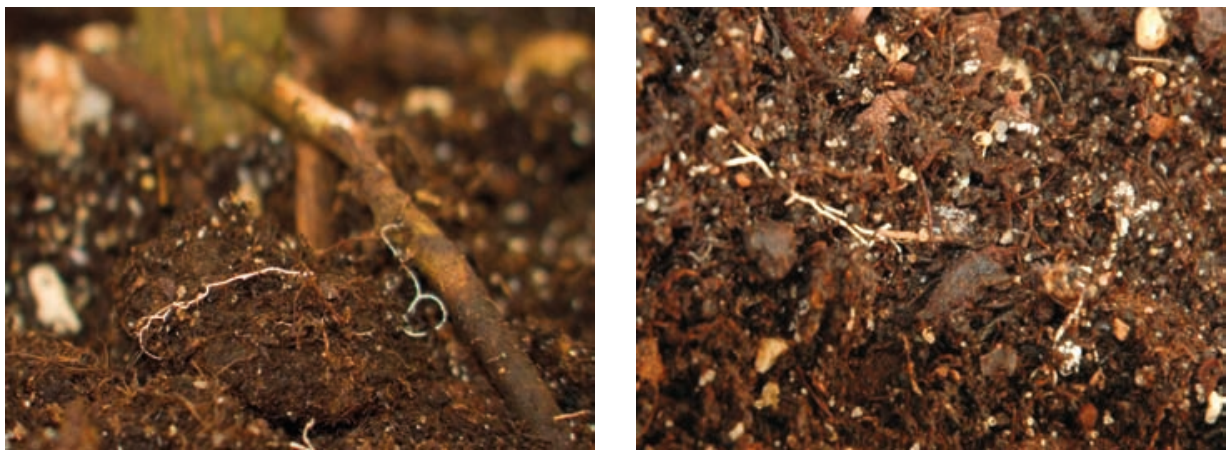

Fig. 3 (left) and Fig. 4 (right) Ectomycorrhiza with roots of Myristica fragrans. Photos: Bob Ursem.

the inner root cells. An additional benefit of ectomycorrhiza is the protection of young seedlings from other pathogens.

Young plants with well developed ectomycorrhizal connections which are visible to the naked eye grow well and are transplanted to the nursery at Delft BG to reach maturity. Plants are placed in a greenhouse with conditions set at 60-70 per cent humidity and with an average day temperature of $27^{\circ} \mathrm{C}$ and an average night temperature of $24^{\circ} \mathrm{C}$. This greenhouse is not misted but the humidity is maintained. Younger plants in particular can be affected by detrimental fungal attacks if exposed to very wet conditions for too long, and black mould fungus (Aspergillus niger), for example, is known to occur in conditions of high humidity (Ursem, 2004). Field observations by Ursem in South Africa recognised that more than 15 minutes' exposure to high humidity can lead to black mould fungus infection in plants of the family Proteaceae. Ursem's observation also correlates with the distribution pattern of Proteaceae in South Africa, Australia and elsewhere, where plants are confined to high mountain ranges with strong winds or near coastal areas with almost permanent wind (Ursem, 2007 \& 2009).

The young plants are mulched with manure after six months. Prior to this they are fed with a 12:0:15 N:P:K solution every two weeks. Nearly all species in Myristicaceae are kept under these conditions, with the exception of Myristica womersleyi from Papua New Guinea which was collected in the Eastern Highlands Province of Mount Michael and Mount Piora. This species was collected at an altitude of 2,000-2,330m in its habitat of steep slopes and ridges of a Cunoniaceae and Nothofagus forest. Species occurring there include Gillbeea papuana (rare), Pullea glabra var. glabra (rare), Schizomeria clemensiae (dominant), S. serrata, Nothofagus grandis, N. rubra (and in the highest ranges also N. pullei) (Flora Malesiana, 2002). In Delft BG we cultivate this species under much cooler conditions at $9^{\circ} \mathrm{C}-15^{\circ} \mathrm{C}$ which corresponds with temperature readings taken in their habitat. The seed is also different from all other species in the genus Myristica. It is larger than the other species at $60-90 \mathrm{~mm}$ in diameter and is covered with dense, rough, dark brown hairs. All other species are hairless and very much smaller in size. 


\section{MATURE PLANTS AT DELFT NURSERY}

The nutmeg collection at Delft BG consists of young plants, and at the time of publication there are approximately 400 individuals. The first species to come into the collection germinated in 2002 and it is still in a vegetative phase. Some plants have been distributed to other gardens and flowered for the first time last season. We hope that they will also flower at Delft BG in 2014, so that the species can be verified. Most of the collection at Delft BG are species in the genus Myristica. A wide range of features of the genus are represented by the following species: Myristica argentea, M. fatua, M. fragrans, M. hypargyraea, M. koordersii, M. speciosa and M. succedanea. These have all been collected from a number of different locations and are recorded with the common name 'Pala' and with precise provenance information. Pala means nutmeg in Indonesian. A range of species occurring in different locations were collected in order to observe and study whether there was any variation in the genetic or chemical make-up within and between species. Studies on the variability of species, their patterns of dispersion and evolution are planned. We also speculate that these species may contain undiscovered edible compounds which could have value for human use.

Most species in the Myristicaceae collection are wild-collected from South East Asia. Examples include the genus Gymnacranthera with G. forbesii and G. paniculata; the genus Horsfieldia, with $H$. irya, $H$. iryaghedi, $H$. laevigata var. laevigata, $H$. palauensis, $H$. polyspherula var. polyspherula and $H$. polyspherula var. sumatrana, $H$. subglobosa and $H$. tuberculata plus an additional 18 unidentified species of this genus; the genus Knema, represented by $K$. conferta, K. lunduensis, K. percoriacea and two further unidentified Knema species. We also have Brochoneura madagascariensis, collected wild in Madagascar. The plants have thrived over the last decade, although problems due to a lack of potassium and iron uptake in the plants have been observed. A Hartig net has been seen on some individuals; nevertheless these plants still seem to have problems in the uptake of these nutrients (Fig. 5). The reasons for this will be part of future studies on the function of ectomycorrhiza. At the moment there is speculation that this poor uptake of nutrients could be due to either the ecological environment of the ectomycorrhiza, the addition of manure to the growing media, or the fact that one or more of the typical species of ectomycorrhiza are not present to enable a good uptake of potassium or iron.

\section{PROPAGATION BY CUTTINGS}

Vegetative propagation of the nutmegs began in 2013 with cuttings taken from the largest plants. We experimented with stem tip cuttings and leaf roll cuttings (Fig. 6). Both types of cuttings were put into the same soil conditions with a fungicidal treatment before insertion. The cutting mix consisted of one-third lava grains and two-thirds a mix of 30 per cent sand and 70 per cent peat. Cuttings were taken from Myristica fragrans, M. globosa and M. succedanea. 


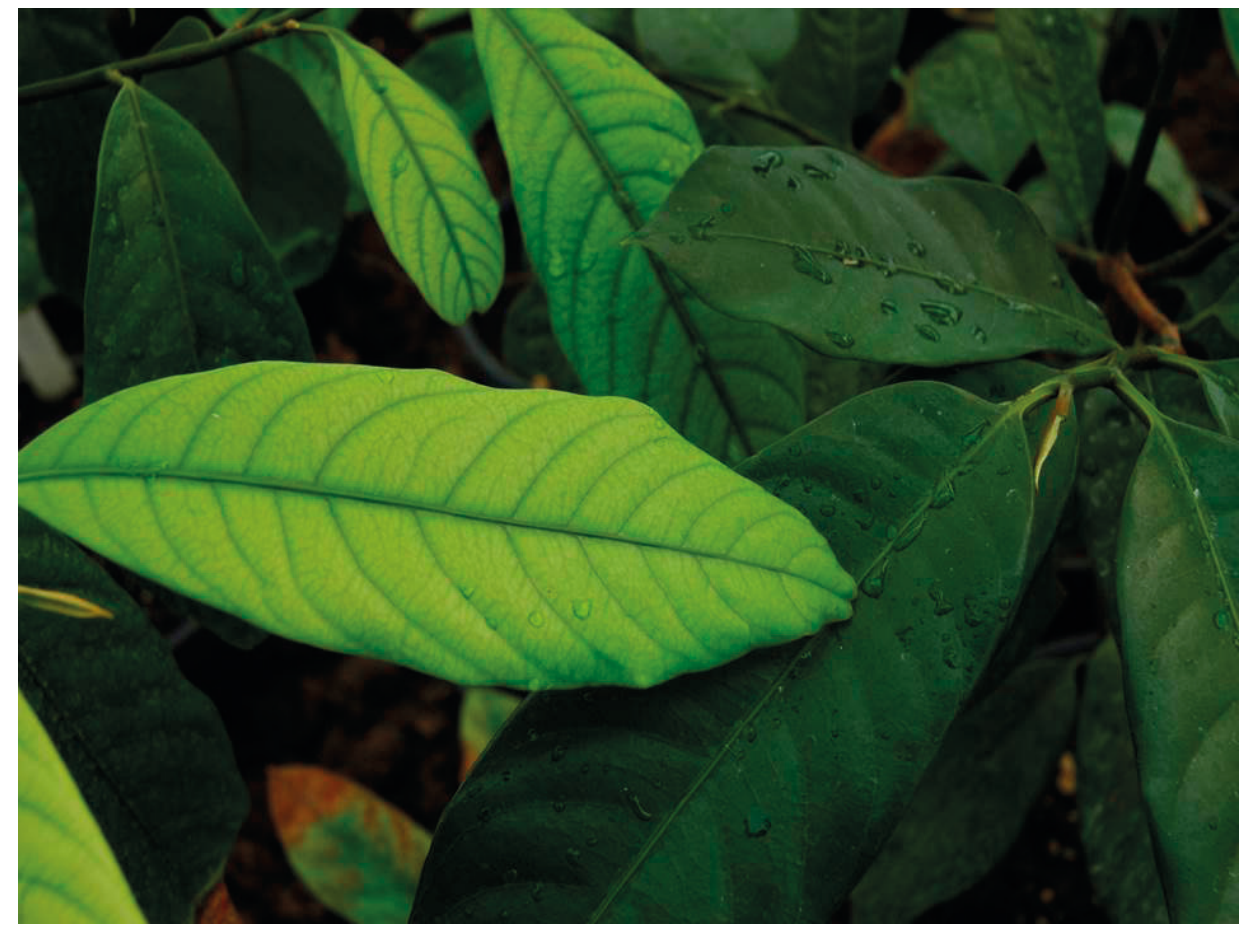

Fig. 5 The pale leaves on the left show the poor uptake of potassium and iron whereas the dark leaves on the right do not have these problems. Photo: Bob Ursem.

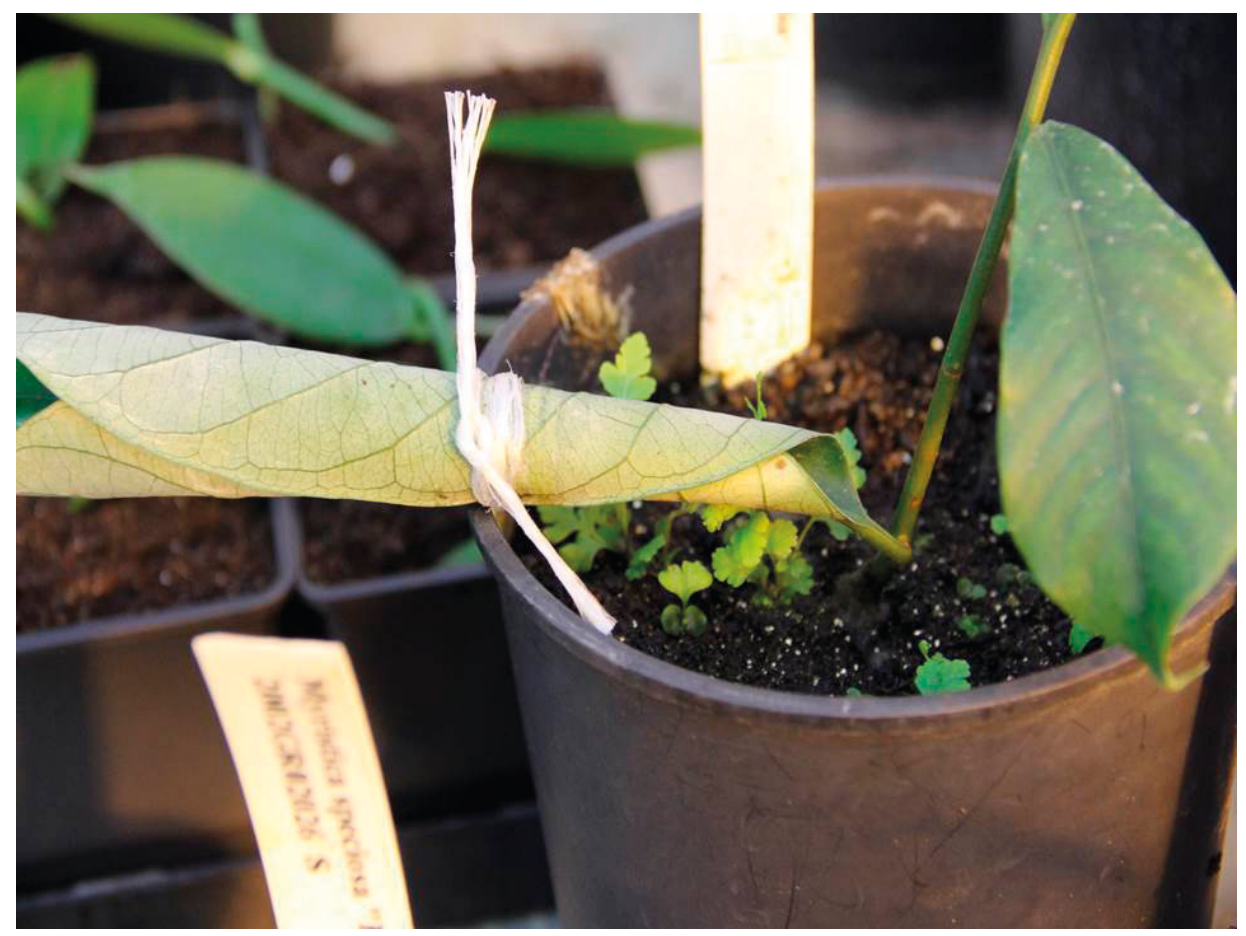

Fig. 6 Leaf roll cutting of Myristica fragrans. Photo: Erwin Kluver. 
Cuttings were first treated by dipping the cut end into a mixture developed by Boesrie at Delft BG, especially for difficult-to-root woody tropical tree species. The mixture contains the following components: Captan, Previcure ${ }^{\circledR}$, Rizolex $^{\circledR}$ and Rhizopon ${ }^{\circledR}$ AA \#1. Captan is used to protect against fungal infections, especially Botrytis. Previcure ${ }^{\circledR}$ contains the active substances Fosetyl and Propamocarb and is also used to protect against fungal infections, especially Phytophthora. Rizolex ${ }^{\circledR}$ is a generic fungicide with the active substance Tolclofos-methyl. Rhizopon ${ }^{\circledR}$ AA \#1 (indole-3-butryic acid) stimulates root formation in woody plants. The mixture was made up as follows: $17 \mathrm{ml}$ of Captan, $12 \mathrm{ml}$ of Previcure ${ }^{\circledR}, 25 \mathrm{ml}$ of Rizolex ${ }^{\circledR}$ and finally two (2\%) tablets of Rhizopon ${ }^{\circledR}$ AA \#1. These were all added to 101 of water. The cuttings were soaked for 15 minutes in this mixture and then potted in the recommended cuttings mix described above. Another three sets of stem cuttings were taken and dipped in three separate treatments: Rhizopon ${ }^{\circledR}$ B (0.1\%), Rhizopon ${ }^{\circledR}$ A (1\%) and Rhizopon ${ }^{\circledR}$ AA $(2 \%)$.

After two weeks all cuttings treated with Rhizopon ${ }^{\circledR}$ B, Rhizopon ${ }^{\circledR}$ A and Rhizopon ${ }^{\circledR}$ AA began to decay, while those treated with Previcur ${ }^{\circledR}$ survived. The surviving cuttings were treated again with a solution of Previcur ${ }^{\circledR}$ added to the irrigation water. After four months of irrigation with this solution the cuttings began to form a callus at the base. In the six months that followed the first roots began to appear. Both the stem cuttings and leaf roll cuttings showed positive root development followed by vegetative growth after seven to eight months (Fig. 7).

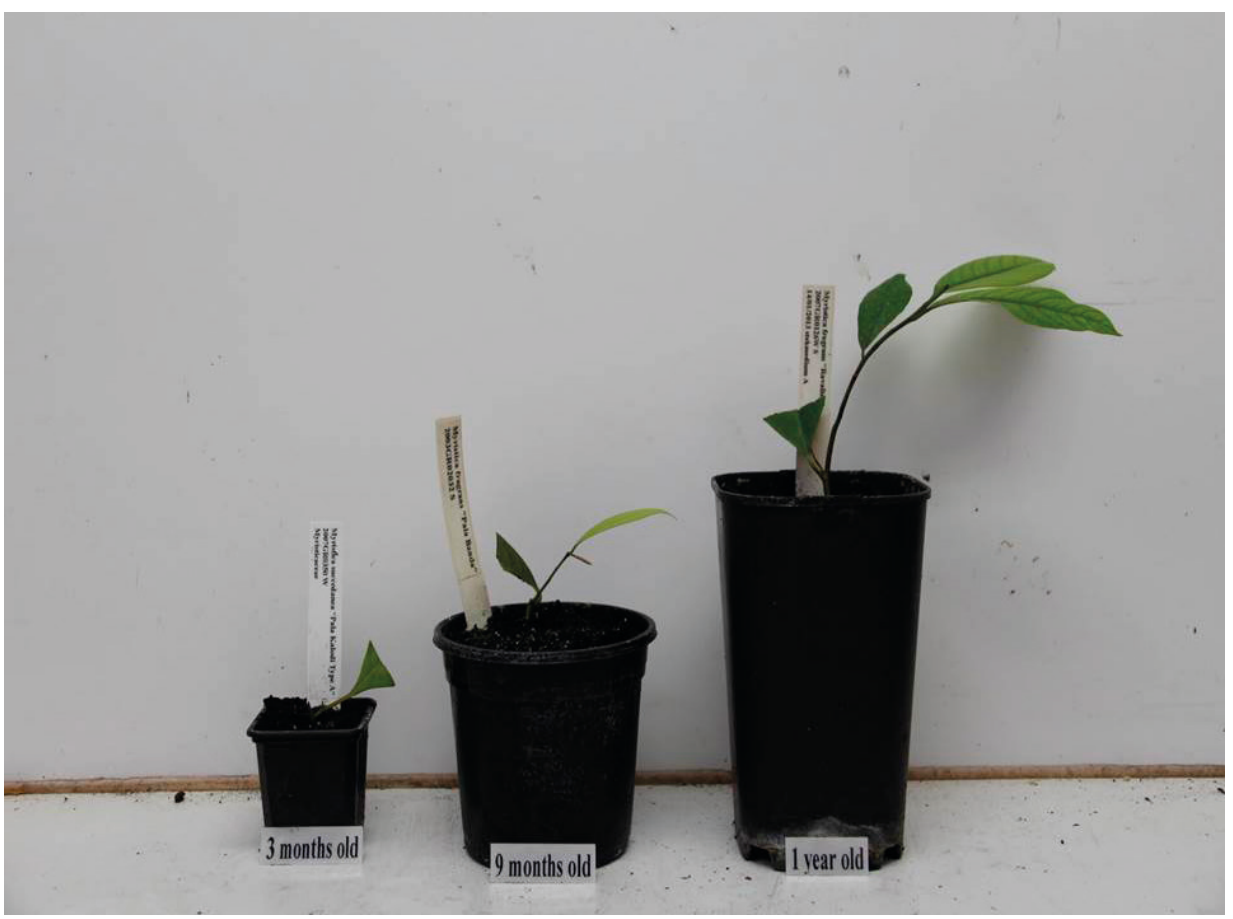

Fig. 7 Development and growth of cuttings of Myristica succedanea. Photo: Erwin Kluver. 
These results are remarkable for this species and represent a breakthrough in the propagation of Myristica which is considered to be almost impossible to root as cuttings. As a consequence of these excellent rooting results, we will continue to use this method to propagate other genera in the family such as Brochoneura, Gymnacrantha, Horsfieldia and Knema and look forward to reporting on this in future. The combination of Boesrie's rooting mixture and the quick connection with ectomycorrhiza is essential for good propagation and growing results with these plants and we intend to continue to research the value of this method for other woody species which are difficult to propagate vegetatively. We also look forward to receiving comments and results from other botanic gardens who are growing these species and may use the cultivation and propagation methods described here.

\section{REFERENCES}

BAAR, J. \& OZINGA, W.M. (2007). Mycorrhizaschimmels sleutelfactor voor duurzame landbouw en natuur, KNNV Press, Uitgeverij, Zeist.

NOOTEBOOM, H.P. (ed.) (2002). Flora Malesiana, series 1, volume 16. Nationaal Herbarium Nederland, Leiden.

PETERSON, R.L., MASSICOTTE, H.B. \& PHILIPS, F. (2006). Mycorrhiza: Anatomy and Cell Biology Images. CD-ROM, NRC Research Press, Ottawa.

SMITH, S.E. \& READ, D.J. (2008). Mycorrhizal Symbiosis. Academic Press, San Diego, CA.

URSEM, W.N.J. (2004). Ex situ horticulture of Welwitschia mirabilis. Sibbaldia 2: 47-50.

URSEM, W.N.J. (2007). Plant mycorrhiza and its importance in horticulture. Presentation to the European Mycorrhiza Symposium, Delft.

URSEM, W.N.J. (2009). Plant mycorrhiza and its importance in horticulture. Presentation to Eurogard V, Helsinki. Available at: http://www.botanicgardens.eu/eurogard/eurogard5abs. htm (Accessed: 1 July 2014).

VAN MOURIK, P. \& VAN DER VEEN, G. (2008). From Plant to Technology. VSSD Press, Delft.

WALKER, C. (2013). Arbuscular mycorrhiza in the Living Collections at the Royal Botanic Garden Edinburgh. Sibbaldia 11: 143-158. 
